DOI 10.37882/2223-2974.2020.09.03

\title{
КРИТЕРИИ НЕВМЕНЯЕМОСТИ И ИХ ПРИМЕНЕНИЕ В ЗАКОНЕ И СУДЕБНО-СЛЕДСТВЕННОЙ ПРАКТИКЕ
}

\section{CRITERIA OF INSANITY AND ITS APPLICATION IN THE LAW AND JUDICIAL AND INVESTIGATORY PRACTICE}

\section{Belyankina}

Summary: In this article, the author substantiates the selection of the criteria for insanity in criminal law science. The relevance of this topic is determined by a combination of problems in criminal law and forensic psychiatry, where insanity is considered in the pathology of the human psyche and their manifestations. The statement that the violation of behaviour and interaction with the outside world in a person occurs in the event of a mental illness, allows you to separate the concepts of "sanity» and «insanity» in the legislation. The main criteria considered: medical (biological), psychological (psychiatric) and legal (criminal law). The analysis of the above criteria for insanity made it possible to conclude that it is important to conduct a forensic medical examination to eliminate contradictions. The purpose of this work is to formulate the basic concept of insanity and its criteria, with special attention paid to three signs of the legal criterion of insanity, on the basis of which the legal criterion is not only a set of signs, but also the rationale for declaring a subject insane. The study of regulatory documents in the field of criminal law, forensic medical examination allowed the author to identify gaps in the field of law enforcement, namely, the absence of a specific, unified algorithm of action to determine the insanity of a subject.

Keywords: insanity; medical criterion, psychological criterion, legal criterion, tort, circumstances excluding liability.
Белянкина Валентина Александровна

К.nсх.н., старший преподаватель, Санкт-Петербургский университет МВД России, г. Санкт-Петербург

kinatina@mail.ru

Аннотация: В настоящей статье автор обосновывает выделение критериев невменяемости в уголовно-правовой науке. Актуальность данной темы определяется сочетанием проблематики в уголовном праве и судебной психиатрии, где невменяемость рассматривается в патологии человеческой психики и их проявлений. Констатация, что нарушение поведения и взаимодействия с окружающим миром у человека происходит в случае наличия у него психического заболевания, позволяет развести понятия «вменяемости» и «невменяемости» в законодательстве. Основные рассматриваемые критерии: медицинский (биологический), психологический (психиатрический) и юридический (уголовно-правовой). Проведенный анализ вышеуказанных критериев невменяемости позволил сделать вывод о важности проведение судебно-медицинской экспертизы для исключения противоречий. Целью данной работы является формулирование основного понятия невменяемости и его критериев, при этом особое внимание было уделено трем признакам юридического критерия невменяемости, на основании которых юридический критерий это не только совокупность признаков, но и обоснования для признания субъекта невменяемым. Изучение нормативно-правовых документов в области уголовного права, судебно-медицинской экспертизы позволило автору определить пробелы в области правоприменения, а именно отсутствие определенного, единого алгоритма действия для определения невменяемости субъекта.

Ключевые слова: невменяемость; медицинский критерий; психологический критерий; юридический критерий; общественно опасное деяние; обстоятельства, исключающие ответственность.

ческого лица, совершившего преступление, как один из основных критериев для уголовной ответственности. Ответственность за совершение данных деяний наступает только в случае обладания поступков и действий физического лица сознательным характером.

Действия человека, обусловленные активностью сознания и сознательной же способности к регулированию собственного поведения, не следует считать предопределенными целеполаганием в поведении человека. «Волевое действие человека всегда опосредовано более или менее сложной работой его сознания». Само наличие интеллектуального процесса, напрямую включенного в любой волевой акт, говорит об опосредованности действия человека мыслью, сознательным характером, т.е. осознанием последствий данного действия.

Соответственно, нарушение сложных форм поведения и социо-взаимоотношений человека может про- 
изойти только в случае наличия у него болезненных расстройств психики, симптомов и синдромов, приобретенных в случае возникновения и развития у него определенного психического заболевания.

Психозы приводят к нарушению отражательной деятельности мозга и, соответственно, приводит к практическому отсутствию у человека сознательного отношения к своему действию, регулированию своего поведения из-за искажения отражения реальной действительности и объективных социальных отношений. Нарушения социальных взаимоотношений, вызванные болезненными расстройствами психики, могут привести к совершению человеком общественно опасных действий, за которые, однако, он не может нести личную уголовно-правовую ответственность. Именно исключение ответственности лица вследствие болезненных нарушений психики и приводит к проблеме невменяемости. Понятие невменяемости лица в отношении к понятию вменяемости лица является негативным и предопределяет общие критерии нарушения психической деятельности лица, вызванного болезнью, ведущие к исключению юридической ответственности.

Для начала рассмотрим юридические понятия «вменяемости» и «невменяемости», данные термины делают упор на психическую деятельность субъекта. Существует научно-материалистический подход понимания проблемы невменяемости, он закреплён в уголовном законодательстве, суть его показать критерии, по которым можно аргументировать вменяемость или же невменяемость. Если рассматривать биологизацию и не социальное поведение субъекта, то можно заметить, что всё чаще путают понятия о проявлении болезни и уже прогрессирующей психической болезнью, а также не все различают принудительное лечение и меры иного наказания. В.Н. Кудрявцев делает упор на биологический фактор, субъект с патологической аномалией не может совершить преступление умышленно, он может выполнить только одно из условий преступного поведения. Но если такие факторы становятся опасными и могут быть направлены на действия против закона, то в этом случае стоит переходить к медицинской сфере, и из этого следует, что затрагивается уже не факт противоправного действия, а действия, связанные с психическим расстройством [3, с. 7]. Эти понятия имеют разное значение в законодательстве.

В уголовном законодательстве прописывается понятие о том, что такое «невменяемость в т. н. «формуле невменяемости», данная формула включает в себя критерии, помогающие дать более расширенное объяснение. Проводя анализ психического состояние субъекта, эксперты должны написать заключение, используя критерии. Саму формулу вы можете найти в ст. 21 УК РФ.
Важный и необходимый признак субъекта при совершении преступления - это вменяемость, т. е. достаточное психическое здоровье, лицо может быть привечено к ответственности только тогда, кого оно понимает и оценивает свои действия, отдает им отчет и может их контролировать.

Если мы обратимся к ч. 1 ст. 21 УК, то увидим, что субъект не может быть признан виновным, если при совершении опасного преступления он был невменяемым, т. е. он не отдавал отчет своим действиям и не осознавал их последствий, а также, если у него будет обнаружено и доказано временное или постоянное психическое расстройство, либо иное нарушение психики. Для того чтобы лицо привлекалось к уголовной ответственности, необходимо доказать наличие его вины в том деяние, в котором его обвиняют (ст. 5 УK).

Некоторые субъекты не могут совершать деяние умышленно, если подвержены психическим болезням и расстройствам, так как они не в состоянии контролировать собственное поведение и совершаемые ими опасные действия, а это означает, что такие субъекты не проявляют вину по закону. Такие дела рассматриваются судом, определяется может ли лицо за совершенное преступное деяние нести ответственность и наказание, если он невменяем.

Если субъект с психическим заболеванием совершает действие против закона, то ему полагается лечение. Из этого следует, что прежде, чем ему будет предъявлено обвинение, и если он достиг возраста, при котором может отвечать за свои поступки, также должно быть заключение о его вменяемости.

Понятие о том, что такое вменяемость, также закреплено в уголовной доктрине права: «Вменяемость есть способность лица сознавать во время совершения преступления фактический характер и общественную опасность своих действий (бездействия) и руководить ими, обусловливающая возможность лица признаваться виновным и нести уголовную ответственность за содеянное, т.е. юридическая предпосылка вины и уголовной ответственности».

И тогда получается, что лицо может быть обвиняемым, только в том случае, если будет подобрана доказательная база и заключение от экспертов о том, что у него психическая болезнь и субъект не мог совершить деяние умышленно. Однако субъект, который совершил преступление и нарушил закон, должен осознавать какова социальная значимость его деяний и какой характер преступления оно несет. Лицо не может обвиняемым без доказательства о содеянном, а также не может являть невменяемым без совершения деяния. 
Критерии понятия невменяемости помимо того что представлены формулой, также изложены в ч. 1 ст. 21 УК РФ («Невменяемость»), исходя из неё «не подлежит уголовной ответственности лицо, которое во время совершения общественно опасного деяния находилось в состоянии невменяемости, то есть не могло осознавать фактический характер и общественную опасность своих действий (бездействия) либо руководить ими вследствие хронического психического расстройства, временного психического расстройства, слабоумия либо иного болезненного состояния психики».

В уголовном законодательстве не прописывается отдельным пунктом что такое «критерии», ответ на данный вопрос можно найти в специальной справочной литературе, данное понятие толкуется как «мерило оценки, суждения» [3, с. 18].

Используемый нами термин мы можем рассматривать через предмет исследования, но только тогда, когда сможем дать точное определение слову «невменяемость», выяснить, какие критерии необходимы для него, а также выделить общие черты.

В ходе исследования мы выяснили, что существует формула «невменяемости», однако разные авторы подходят к этому понятию по-своему и не существует единого мнения. Рассмотрим на примере отечественной литературы и различных авторах, продемонстрируем несколько подходов и разнообразных позиций.

Критерии, которые применяются к термину «невменяемость» не противоречат законодательной формулировке ч. 1 ст. 21 УК РФ, однако, они не затрагивают и не дает ответа на вопрос о констатации невменяемости того или иного субъекта.

Итак, некоторые авторы при установлении невменяемости опираются на судебно-психиатрическую(ие) экспертизу (экспертизы), другие же авторы в своей литературе настаивают, что необходимо оценивать, также, как и другую доказательную базу по совершаемому деянию; следующие упоминают, что субъект может признан невменяемым, если так решит применитель права, который также в своих суждениях должен опираться на экспертизу, однако, следует учитывать. Что если в ходе дела у суда или у других лиц возникают сомнения, то возможно назначение повторной судебной экспертизы, но более повышенного уровня; также авторы говорят, о том, что если у них появляется несогласие или сомнение в проведённой экспертизе, по отношению к обвиняемому субъекту, то они должны объяснить, почему и предоставить доказательств; следующие выделяют, что медицинский критерий основывается на специалисте в этой области, однако, если рассматривать юридическую сторону, то она уже действует из решения правоприменителя, опираясь не только на проведенную психиатрическую экспертизу, но и на факты, доводы и доказательства; авторы также проводят и показывают связь между психиатрической экспертизой, которая основывается на нескольких критериях, таких как психологический и медицинский, но и критерий «невменяемости» закрепленный в законодательстве, или опирается на решение правоприменителя о невменяемости.

Обратим внимание на позицию, изложенную в абзац 2 п. 6 постановления Пленума ВС РФ от 7 апреля 2011 г. N 6, «при назначении судебно-психиатрической экспертизы на разрешение экспертов следует ставить вопросы, позволяющие выяснить характер и степень психического расстройства во время совершения предусмотренного уголовным законом общественно опасного деяния, в ходе предварительного расследования или рассмотрения дела судом, установить, могло ли лицо в указанные периоды осознавать фактический характер и общественную опасность своих действий (бездействия) либо руководить ими».

В ходе доказательства и анализа такой критерий, как психологический, не всегда может быть ясно выражен, так как есть несколько сторон, одна опирается на решение психиатрической экспертизы, чтобы представлять диагноз обвиняемого субъекта, а также указывает насколько велико у субъекта расстройство, показывает на какой стадии находится его расстройство, однако другая сторона делает упор на медицинский критерий и на рассмотрение дела в судебном порядке.

Из чего мы делаем вывод, что термин невменяемость трактуется по-разному, и это можно проследить, а также, как правило, устанавливается применителями права.

Проанализировав ряд статей УПК РФ, мы можем прийти к определённому выводу. Согласно п. 3 ст. 196 УПК РФ для того, чтобы установить психическое состояние обвиняемого лица, необходимо проводить судебно-медицинскую экспертизу.

Опираясь на ст. 207 УПК РФ, для назначения повторной или дополнительной судебно-медицинской экспертизы, необходима неполнота её проведения иди недостаточные доказательства эксперта-медика, а также при возникновении вопросов по совершаемому деянию, также возможна повторная экспертиза при наличии сомнений в компетентности эксперта или противоречия в его заключении.

Указанные выше факторы, полностью доказывают, что опираться на мнение одного человека недопустимо, так как это решается не только экспертами, но и правоприменителями. 
А в чем же заключается тогда работа юристов? Они доказывают и устанавливают связь и между данными, которые у них уже есть по обвиняемому субъекту, и судебно-медицинской экспертизой, устраняют любые противоречия и смотрят, чтобы не могло возникнуть сомнений по рассматриваемому делу.

При возникновении сомнений в результатах, представленных экспертом, назначается еще одна судебномедицинская экспертиза, правоприменитель не может принимать самостоятельное решение о невменяемости или вменяемости обвиняемого субъекта, без доказательной экспертизы. Это указывается в судебной практике.

Существует один из поводов, при котором можно рассматривать вопрос о принудительных медицинских мерах. Это возможно, когда невменяемость рассматривается как медицинский термин, а юридическая сторона тогда заключается в предоставлении последствий, когда субъект признан невменяемым.

Следует обратить внимание, на тот факт, что медицинские критерии, используемые при проведение судебной экспертизы, не дают 100\% гарантии, о признании субъекта «невменяемым», так как эти действия рассматривают только психику, без доказательной базы и юридических заключений.

Для этого было создано и выделено несколько критериев, по которым определяют невменяемость:

- медицинский критерий;

- психологический критерий;

- юридический или уголовно-правовой критерий.

Существуют и множество других критериев, но они связаны с психиатрией, а не с уголовным правом. Именно поэтому обратимся к юридическому (уголовно-правовому) критерию, определяющему невменяемость субъекта.

Данный критерий начал образовываться вместе с уголовно-правовой мыслью, это происходило в советское время, тогда он и формируется как отдельный критерий, но он не стоит на месте, а изменяется со временем.

Верная позиция заключается в том, что когда происходит характеристика невменяемости субъекта, то она основывается на медицинском уровне.

Происходит распад границ, определяющих невменяемость в ч. 1 ст. 21 УК РФ, и тем состоянием, когда психическое расстройство лишает субъекта на осознание своих деяний по отношению к другим, а также приводит к совершению преступления.

Если рассматривать практическую часть, и опираться на заключение эксперта-медика, то тогда юридическая сторона придерживается и соглашается с выдвинутыми результатами невменяемости.

Как мы выяснили, юридический критерий подвергается большому количеству обсуждений и подходов разными авторами, но если учитывать уголовный закон и постановления Пленума ВС РФ от 7 апреля 2011 г. N 6 то отсюда вытекает вывод, что данный критерий представляется тремя признаками.

Первым признаком будет являться преступление, совершенное субъектом в возрасте, достигающем наказания, которое может трактоваться как опасное для жизни других, или нарушает признаки уголовно-правового запрета, предусмотренного статьями Особенной части УК PФ.

Таким образом, первый признак юридического критерия указывает на деяние субъекта и его неправомерные действия по отношению к которым возможно заключить судебно-медицинскую экспертизу, доказывающую о вменяемости или невменяемости данного лица.

Общественно опасные преступления содержатся в ст. 21, ч. 1 УК РФ. Данная статья дает понимание термина «невменяемость», а также указывает на то, что совершивший деяние субъект должен пройти медицинскую экспертизу и предоставить заключение врача.

Обращаясь ко второму признаку юридического критерия невменяемости, мы можем сказать, что его называют временным или темпоральным признаком, так как он не только включает факт совершенного субъектом деяния, но и психологический фактор, которые указывают на сознательное или несознательное поведение.

Этот признак также прописан в ч. 1 ст. 21 УК РФ, содержится в таких словах как «во время совершения общественно опасного деяния». Данный признак подкреплён материалами из абз. 1 п. 2 и абз. 2 п. 6 постановления Пленума ВС РФ от 7 апреля 2011 г. N 6, где указывается «на разрешение экспертов необходимо ставить вопросы, позволяющие выяснить характер и степень психического расстройства во время совершения, предусмотренного уголовным законом общественно опасного деяния, в ходе предварительного расследования или рассмотрения дела судом установить, могло ли лицо в указанные периоды осознавать фактический характер и общественную опасность своих действий (бездействия) либо руководить ими».

Последний признак юридического факта, закрепляется в процессуальных документах, где устанавливается вменяемость или невменяемость обвиняемого субъекта. 
Данный признак основывается на результатах, показавших вменяемость или невменяемость субъекта после проведенной судебно-психиатрической экспертизы, учитывая предыдущие юридические критерии.

Применяя третий признак юридического критерия, следует учитывать, что правом определить невменяемость или вменяемость субъекта владеют только органы власти (уголовно-юстиционные), они также могут закрепить это в правовых документах.

Этот признак не находит своё подтверждение в каких-либо законодательных документах, но он прописывается правоприменительной практикой, она указывает на то, что эксперт составляет заключение, в котором указывает, на какой стадии психического расстройства находится обвиняемый субъект, благодаря этому суд может вынести свой вердикт.

Приходя к выводам: если, мы хотим констатировать невменяемость органами власти на основе документов, в которых она прописывается, следует сказать, что происходит искажение термина «невменяемость» при исследовании медиками и использовании судебной экспертизы. Исходя из этого понимания, органы, применяющие право не имеют возможности изучать вопрос, связанный с психическим состоянием субъекта (так как этот вопрос рассматривается в медицинской сфере, а юрист не обладает достаточными знаниями), а также о наличии или отсутствии признаков, при которых можно решить является ли вменяемым субъект или наоборот.

Если выполнена судебно-медицинская экспертиза, которая соединяет мнения экспертов и доказательную базу, если также она не оставляет дополнительных вопросов по рассматриваемому делу, то тогда на неё опирается данный признак.
Исходя из наших заключений и выводов, юридический критерий имеет свой определение - это совокупность признаков, характеризующих как судебную экспертизу, так и юридическое обоснование для признания субъекта невменяемым.

Подводя итоги, мы выделяем существование таких критериев как: медицинский, психологический и юридический, они определяют вменяемость или невменяемость субъекта.

Доказать то, что субъект невменяем могут органы власти, а точнее - дознаватель и следователь, это закреплено в ст. 439 УПК РФ, но решение не искажающие реалии будет использовано после проведения суда.

Это помогает исключить возможную ошибку при вынесении приговора в обвинении и невменяемости, а также будет выбрана нужная степень необходимости применения принудительных мер медицинского лечения субъекту, признанному невменяемым. Необходимо понимать, что субъект с психическим расстройством не способен на самозащиту в суде, нуждается в охране, а также обращения внимания на доказательную базу в ходе судебного процесса, так как они могут являться вменяемыми.

Лица, которые признаны невменяемыми, это субъекты, не отдающие себе отчет в деяниях, предусмотренных статьями Особенной части настоящего Кодекса, осознавать общественную опасность и фактический характер своих действий (бездействия) либо руководить ими вследствие временного психического расстройства, хронического психического расстройства, слабоумия или иного нестабильного состояния психики, установленного судом на основании экспертного заключения.

\section{ЛИТЕРАТУРА}

1. Комментарий к Уголовному кодексу Российской Федерации / под ред. Л.В. Иногамовой-Хегай. - М.: Инфра-М, 2016. - 572 с.

2. Богомягков, Ю.С. Уголовно-правовая невменяемость: критерии и признаки. - М., 2016. - № 4. - С. 103-108.

3. Галкин, М.В., Морозов В.И. К вопросу о критериях невменяемости // Юридическая наука и правоохранительная практика. - М., 2016.

4. Зелинский, А.Ф. Осознаваемое и неосознаваемое в преступном поведении. - М., 2015. - С. 97.

5. Кудрявцев, В.Н. Проблемы причинности в криминологии // Вопросы философии. М., 2015. - № 10. - С. 106.

6. Пестов, Д.А. Проблема невменяемости в уголовном праве // Вестник Тамбовского Университета. Серия: Государство и право. - Тамбов, 2010.

7. Протченко, Б.А. Понятие невменяемости в советском уголовном праве // Правоведение. - М., 2017. - № 4. - С. 82-86.

8. Таганцев, Н.С. Русское уголовное право. Т.1. 2008 С. 144.

9. Спасенников, Б.А. К вопросу о вменяемости подсудимого // Российский судья. 2013. № 4. С. 19-22.

10. Шишков, С.В. Понятия «вменяемость» и «невменяемость» В следственной судебной и экспертной практике // Законность. - М., 2016. - № 2. - С. 25.

() Белянкина Валентина Александровна (kinatina@mail.ru). 